\title{
REPRESENTACIONES DE GÉNERO DE MAESTROS FORMADORES: UNA CASA EN RUINAS
}

\author{
Leidy Yaneth Vásquez Ramírez \\ Especialista en Literatura con énfasis en producción de textos e hipertextos \\ Magister en Educación Universidad de Antioquia \\ todoesfuga@gmail.com
}

\begin{abstract}
Cómo citar este artículo
Vásquez, L.Y. (2013) Representaciones de géneros de maestros formadores: una casa en ruinas. Espiral, Revista de Docencia e Investigación. 3 (2)
\end{abstract}

\begin{abstract}
Resumen
Este artículo presenta resultados parciales del proyecto de investigación desarrollado en el marco de la Maestría en Educación, Línea: Maestro, Pensamiento y Formación de la Universidad Pontificia Bolivariana, titulado: Representaciones de género en docentes formadores de maestros en Lengua Castellana en dos universidades de la ciudad de Medellín. En este sentido, implementa algunos postulados del modelo emergente de la teoría fundamentada, principalmente la codificación abierta, a partir de los cuales presenta algunas reflexiones en torno a la manera como las representaciones de género de los maestros formadores de formadores en Lengua Castellana están determinadas y caracterizadas, entre otros factores, por las experiencias hegemónicas de formación y la relación entre género y saber; finalmente, este recorrido permite establecer una relación entre representación de género y formación como posibilidades de ser en y con el Otro, en tanto componente fundamental para la formación de Licenciados en Lengua Castellana.
\end{abstract}

Palabras clave: representaciones de género, experiencias hegemónicas de formación, género y saberes, formación de formadores.

\footnotetext{
Abstract

This paper presents partial results of a research project developed within the framework of the Master's degree in Education line: Teacher, Thought and Training from Universidad Pontificia Bolivariana, entitled: Representations of gender in trainers of Spanish Language teachers at two universities in Medellin.In this sense, it implements some of the postulates of the emerging model of grounded theory, mainly open coding, from which it presents some reflections on how gender representations of trainers of Spanish Language teachers are determined and characterized, among other factors, by the hegemonic training experiences and the relationship between
}

gender and knowledge, and finally, this tour allows us to establish a relationship between gender representation and training as likely to be in and with the Other, being a fundamental component for Graduate training in Spanish language.

Keywords: representations of gender, hegemonic training experiences, gender and knowledge, training of trainers

\section{Introducción}

\section{Frente a las puertas: el extrañamiento y las preguntas sobre Género y Educación}

Los seres humanos cargamos con un dolor de casa, tenemos añoranza por ese espacio interior que sin duda alguna nos da unidad y nos complejiza simultáneamente. La casa nos brinda un tiempo y un cuerpo para habitar el mundo desde la idea primigenia de un rincón propio, una postura personal, una visión de mundo que alienta nuestras búsquedas de sentido para lo que hacemos en tanto seres humanos, en tanto investigadores. Somos producto de todas las casas que recordamos y que nos han albergado, algunas de ellas construidas sobre bases ajenas, otras en ciernes, como en el caso de los espacios en los que habita el Otro, complejo en sus diferencias, cercano en su corporalidad. Pero, ¿es posible encontrar un solo lugar donde las ruinas de lo que hemos sido nos permitan reflejar nuestras sombras en sus muros? 
La casa que nos ocupa en este trabajo es pública y personal al mismo tiempo. Está rodeada de portezuelas que por varios años han impedido ver y dimensionar lo que realmente hay detrás de los muros que vigilan el vínculo entre género y educación. De esta forma, pese a que habla de nosotros mismos, de esa labor docente que nos da uno de tantos lugares posibles para hacer el relato de nuestra historia, también habla de una sociedad encerrada en sus tradiciones, apresada por las puertas que solo se entreabren para algunos, mientras que continúan estrechándose para otros hombres y mujeres, a conveniencia de unos dueños que las han impuesto.

Nuestra propuesta es buscar cómo actúa ese rincón que nos instala como docentes en la casa de las representaciones de género, irrumpir en esa casa, escuchar sus verdades, cuestionar la manera como se emplazan en nuestra sociedad y específicamente en la formación de formadores en Lengua Castellana en las Facultades de Educación de la ciudad de Medellín, en tanto consideramos, de entrada, que la enseñanza de la lengua y la literatura es un elemento determinante para la formación de los estudiantes desde la perspectiva de género, no solo desde el lenguaje, sino fundamentalmente desde lo simbólico, que es justamente desde donde se instauran las brechas entre hombres y mujeres.

Como estudiantes de la Licenciatura en Lengua Castellana, muchos de nosotros fuimos formados con base en unos contenidos y conocimientos curriculares en los que los docentes privilegiaban los saberes construidos por los hombres y, por tanto, había una mínima aparición de las mujeres o del criterio de la diversidad en estos contextos de divulgación del conocimiento. Desde esta perspectiva, nuestra preocupación inicial se orienta a determinar qué tan conscientes son los docentes acerca de esta presencia, ausencia o encubrimientos que se hacen en el currículo como práctica, pues tal como lo advierte Moreno (2006): "[...] ese modelo masculino que se presenta como superior no corresponde a todos los hombres, sino a aquellos que se identifican con una forma particular de ser hombre vinculada al ejercicio del poder" (p.105).

En esta línea, también sería necesario preguntarnos si la hipótesis de que existe una exclusión de las mujeres en la representación de género de los docentes, y que es lo que plantea este texto, es considerada o no como un problema para los docentes, en el campo del discurso de género como dispositivo de poder (Butler, 2007). En este sentido, nuestras preguntas orientadoras son: ¿Qué representaciones tienen los docentes formadores de formadores en torno a la perspectiva de género? ¿Las representaciones de género permean o no las prácticas de formación, deformación o deconstrucción de feminidades y masculinidades desde los criterios de formación de docentes en Lengua Castellana en la Educación Superior?

\section{Advertir un problema de investigación}

Entremos, ahora, a la casa. Parece que es familiar, pero todo en ésta nos puede sorprender desde los escalones que otros han andado hasta las grietas nuevas que nunca antes nos dolieron tanto. En este trayecto para reconocer aquello que por cercano no es menos intrigante, nos interesan particularmente los docentes formadores de formadores en Lengua Castellana por dos razones. La primera de ellas tiene que ver con nuestras historias de vida personales, pues toda investigación parte de una pregunta íntima que nos hacemos a nosotros mismos y que luego necesita de las voces de otros para recorrer sus caminos. Como investigadores en el campo de la educación y situados también como maestros, sería imposible desligar nuestras experiencias subjetivas de aquello que nos forma, transforma y nos mueve a interrogarnos acerca de las cosas que nos pasan y del porqué suceden así. Una investigación de este tipo, en la cual se indaga por una representación del Otro, no podría trazar fronteras entre nuestras experiencias personales como docentes de Len- 
gua y nuestro deseo de reconocernos también como tales en el espejo del Otro. La segunda razón tiene que ver con un elemento teórico que se ha constituido en el eje central de algunas de las posturas más críticas frente a la construcción de la categoría de género y tiene que ver con el objeto de estudio del docente de Lengua Castellana: el lenguaje. Somos conscientes del poder que posee el lenguaje para subordinar, tal como nos lo recuerda Butler: "El lenguaje es una de las prácticas e instituciones concretas y contingentes mantenidas por la elección de los individuos y, por lo tanto, debilitadas por las acciones colectivas de los individuos que eligen" (2007, p.87). Asimismo, nos recuerda que justamente el individuo adquiere la inteligibilidad de sujeto en el lenguaje, su existencia y su potencia están determinadas por la condición lingüística (Butler, 2001)

Para ello, encendemos una de nuestras pequeñas lámparas en este sótano de las representaciones y nos proponemos como objetivo general de esta investigación: analizar las representaciones de género que tienen los docentes formadores de maestros de Lengua Castellana en dos universidades de la ciudad de Medellín en el segundo semestre del año 2010 y el primero de 2011. En esta línea planteamos como objetivos específicos: 1) Describir las categorías asociadas con las representaciones de género que tienen los docentes de los programas de Lengua Castellana en dos universidades de la ciudad de Medellín; y 2) Interpretar de manera reflexiva las relaciones entre la categoría de "representaciones de género" y las categorías emergentes asociadas a ésta en el análisis de lo planeado y experienciado en la formación de docentes de Lengua Castellana en Educación Superior.

\section{El cajón de los conceptos: las categorías del estudio}

Con la curiosidad de quien abre un cajón en el que se han puesto cosas importantes para las dinámicas cotidianas de la casa, nos acercamos

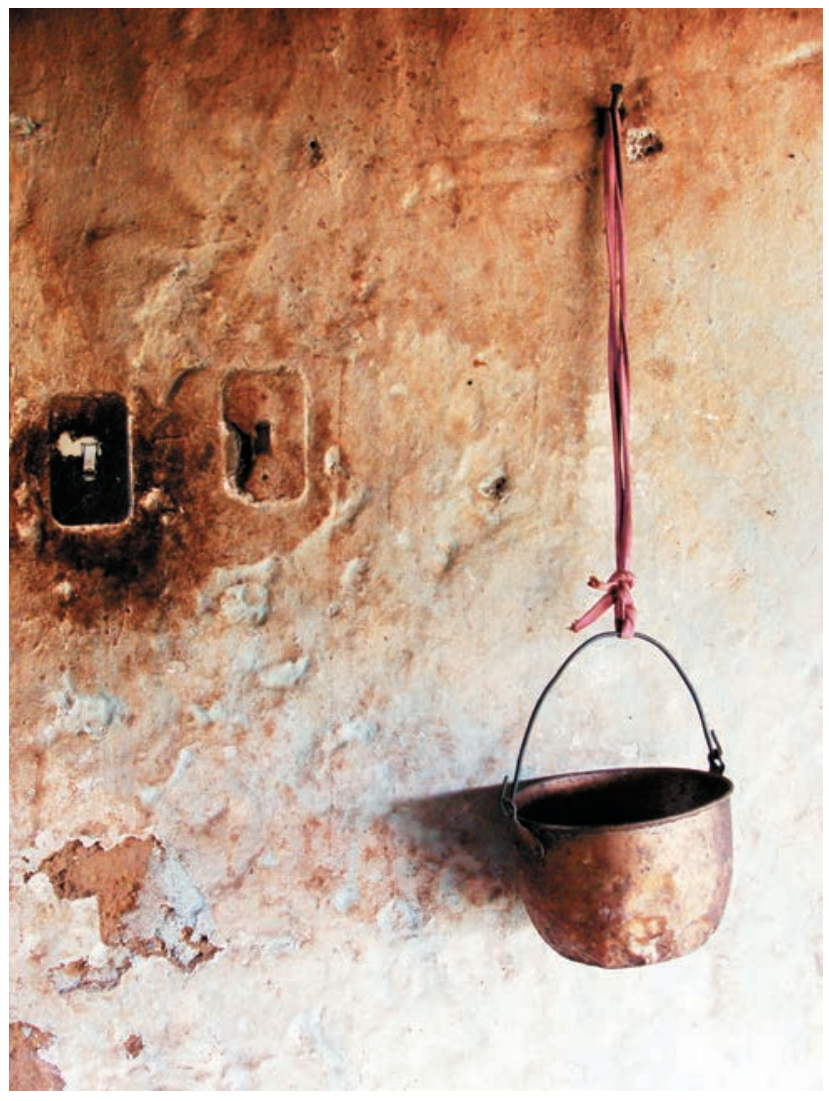

a los conceptos; todos ubicados en el armario principal, algunos mejor dispuestos que otros; en ellos apenas si se alcanzan a distinguir las líneas de frontera que los ubican en relación con sus vecinos cercanos y es justamente en esa diversidad donde radica su poder. No olvidamos aquí que para Bachelard (1993) los mismos conceptos son cajones que nos permiten clasificar el conocimiento, al tiempo que desindividualizan lo vivido por los sujetos.

Tal como lo evidenciamos en el apartado precedente, creemos pertinente darle un giro (así inicialmente sea imperceptible en su potencia) al trabajo conceptual en torno al vínculo entre género y educación, pues no lo consideramos un ejercicio de comprobación de las teorías que han puesto sus ojos en él y lo han ilustrado, en tanto creemos más en la urgencia de construir y reconstruir dicho vínculo, ya no solo desde los planteamientos de los estudios de género como categoría de análisis, absolutamente valiosos y potentes, sino desde la 
develación de las representaciones de género- como categoría central y no tan difundida-, que hace posible la brecha señalada e incluso denunciada desde los enfoques de dichos estudios y a cuya lectura comprensiva apenas estamos acercándonos.

Así las cosas, consideramos que tanto la categoría de "representación" como las de "género" y "representaciones de género", centrales en nuestro trabajo, son construcciones en constante evolución y discusión en lo que se refiere a los estudios de género y por tanto, no caben en un cajón único o unidimensional. Así pues, sabemos que la palabra "género" es inicialmente problemática, pues como sostiene Judith Butler (1990), el género no es algo que esté predeterminado de manera natural o verdadera"[...] no está pasivamente inscrito sobre el cuerpo y tampoco está determinado por la naturaleza, el lenguaje, lo simbólico o la apabullante historia del patriarcado, el género es lo que uno asume (p. 314).Así pues, el género se presenta en nuestra relación con los otros, se refiere a un acto sobre el cual median nuestras decisiones $y$, por tanto, no es un asunto fijo.

Se puede afirmar que el interés por el género como categoría analítica surge a finales del siglo XX desde diferentes constructos teórico y, en esta línea, autores como Navarro y Stimpson (1999) consideran que: "El género es una forma de clasificar los fenómenos de la vida en masculinos, femeninos y neutros" (p. 7). Es tan natural y presente como lo es el tiempo, un ejemplo de ello es preguntar cuando alguien nace si es niño o niña. Sin embargo, el punto central de los estudios de mujeres sobre género es la diferenciación de sexo como condición biológica, y género como normas y comportamientos sociales y psicológicos, con lo cual el género pasaría a ser una construcción social, en tanto parece claro que "[...] los significados de ser macho y hembra no han sido universales; muy por el contrario, han sido locales, inestables y mutables" (Navarro y Stimpson, 1999, p. 9).
De este modo, el concepto de género tiene una aplicación educativa que consideramos importante explorar en tanto se traduce en una representación social que se vincula, tal como ya lo hemos visto, con lo afectivo, lo simbólico y lo cognitivo; en consecuencia, lo anterior da lugar a tipos de comportamientos explicativos de la realidad que se manifiestan a través de las representaciones que se construyen alrededor de la categoría.

El género se vincula, por ende, con las construcciones culturales y discursivas, sin embargo, sería contradictorio intentar una definición unívoca, pues la cuestión se vuelca hacia un interés en el lenguaje, el simbolismo, el sentido y la representación de la definición de género, tal como nos lo recuerda AlonsoGeta (2007). La finalidad de los estudios en torno a la categoría de género es analizar la concepción cultural de lo que es ser mujer o ser hombre, no desde una mirada biologista centrada en el cuerpo que es variable, sino más bien desde "[...] las distintas formas de entenderlo culturalmente, y con el significado mismo de ser hombre y de ser mujer" (Pérez Alonso-Geta, 2007, p. 7).

Por su parte las representaciones, en términos de Silva (2007), se entienden como memoria colectiva y nos interesa verlas como reconstrucciones en función del presente, es decir, representaciones sociales que han sido construidas sobre diálogos, a veces directos otras veces ocultos, en torno a experiencias y creencias sobre el género que se conservan mediante esfuerzos que, en la mayoría de los casos y como sucede con otras categorías sociales e históricas, son conscientes e institucionales.

Desde estos supuestos asumimos las representaciones de género como procesos culturales no conscientes manifestados en lo emotivo y que requieren, por tanto, de análisis del lenguaje y del discurso. Así, las representaciones también se pueden ver en 
canciones, lugares de encuentro, publicidad, libros usuales (Canavessi, 1998) y en aspectos como mitos, creencias, símbolos y elementos de la religión que se deben contrastar con la concepción del conocimiento, la subjetividad y el hacer cotidiano de las personas involucradas en el proceso.

\section{Metodología para recorrer la casa}

No se puede caminar la casa de las representaciones sin rumbo fijo, siempre queda la posibilidad de perderse. Habrá algún objeto para tropezarse, algo que incomoda los pies, sobre todo cuando nos descalzamos. Sin pretender la certeza de las verdades absolutas, es imprescindible ponerse los lentes, no unos de aumento, ni aquellos cuya miopía se nos vuelve cómoda; estos lentes son posibles desde el planteamiento de un diseño mixto como el que desglosamos a continuación, partiendo de la definición del método y el paradigma hasta llegar a la metodología propuesta como tal. Para comenzar definimos el paradigma de nuestra investigación y a continuación nos centramos en el método para abordar el problema alrededor de las representaciones de género que tienen los docentes formadores de formadores en la ciudad de Medellín.

Así las cosas, situamos nuestra investigación en el paradigma cualitativo. Cuando hablamos de investigación cualitativa, y siguiendo a Strauss y Corbin (2002), nos referimos a

[...] cualquier tipo de investigación que produce hallazgos a los que no se llega por medio de procedimientos estadísticos $u$ otros medios de cuantificación. Puede tratarse de investigaciones sobre la vida de la gente, las experiencias vividas, los comportamientos, emociones y sentimientos, así como al funcionamiento organizacional, los movimientos sociales, los fenómenos culturales y la interacción entre las naciones (p. 11-12).

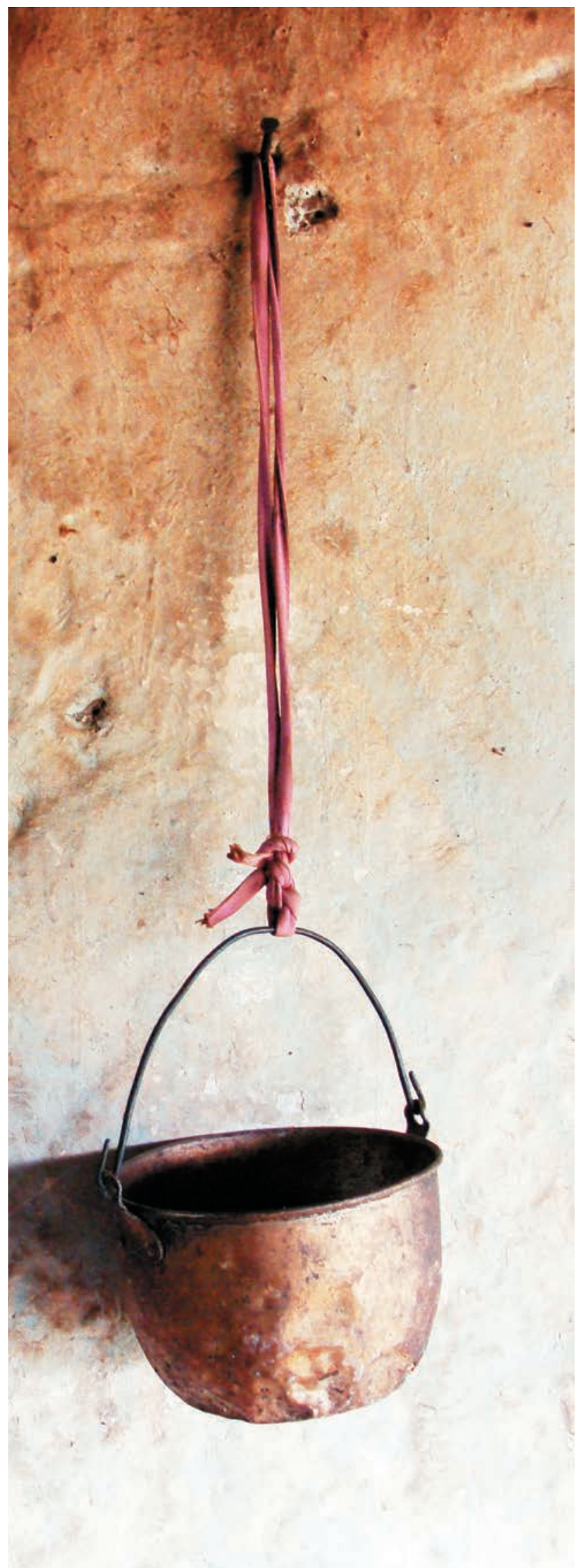




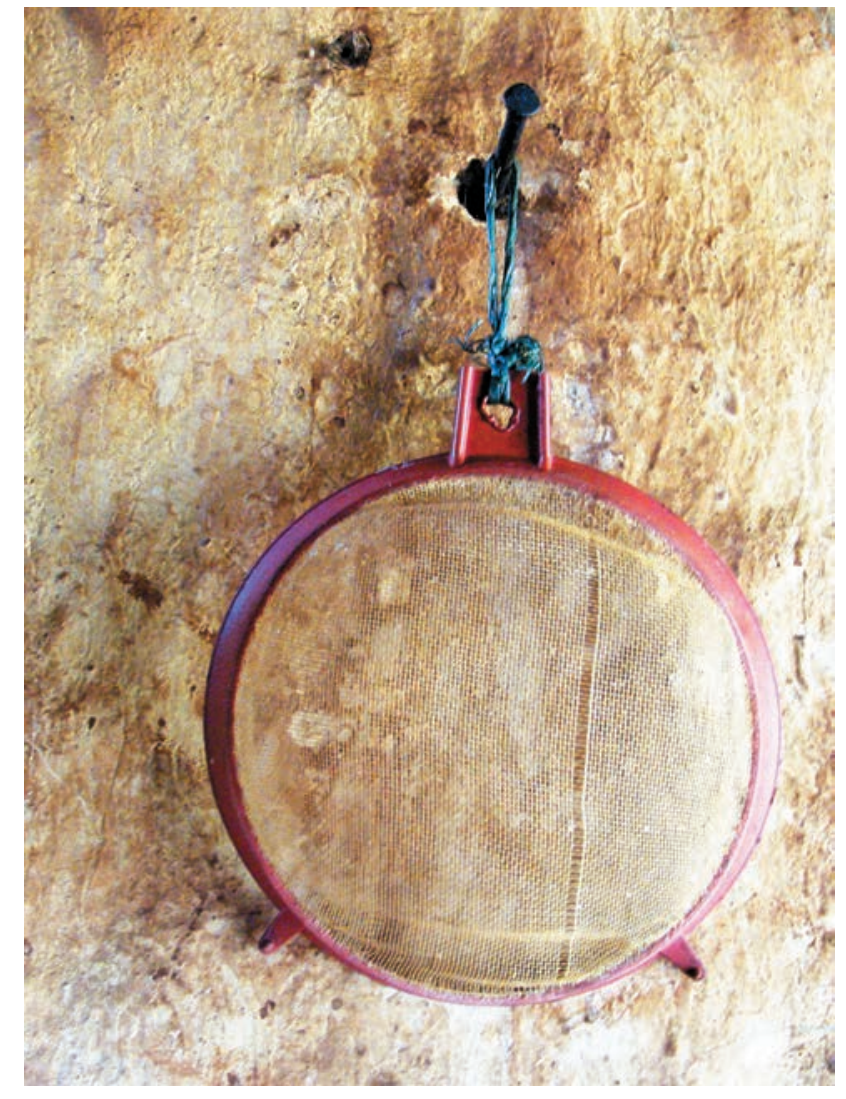

En este orden de ideas, la perspectiva de la investigación cualitativa que asumimos se basa en tres componentes principales: los datos, provenientes de entrevistas, observaciones, registros; los procedimientos, para interpretar y organizar los datos; y las conceptualizaciones que generan categorías (Strauss y Corbin, 2002).

En este sentido, la primera ruta que debemos trazar en nuestros mapas tiene que ver con los procedimientos para la selección de la población. Optamos, entonces, por seleccionar una población focalizada en dos instituciones de Educación Superior de la ciudad de Medellín en las cuales se ofrecen programas de formación de formadores con línea en Lengua Castellana y que puedan otorgar elementos de contraste para el análisis de la información, de manera que los datos no estén viciados por una sola visión. Nos inclinamos por seleccionar una muestra por cuotas y por conveniencia de Formadores de formadores (de cátedra, vinculados y ocasionales) del programa de Licenciatura en Educación
Básica con Énfasis en Humanidades y Lengua Castellana de la Universidad de Antioquia (institución de carácter público) y la Licenciatura en Educación Básica con Énfasis en Humanidades, Lengua Castellana e Idioma Extranjero (inglés) de la Universidad Pontificia Bolivariana (institución de carácter privado) del segundo semestre de 2010 y primer semestre de 2011, que tienen a su cargo distintos cursos del programa de formación de las dos licenciaturas. Ante este panorama elegimos la entrevista semiestructurada pues en ésta "[...] es más probable que los sujetos entrevistados expresen sus puntos de vista en una situación de entrevista diseñada de manera relativamente abierta que en una entrevista estandarizada o en un cuestionario" (Flick, 2007, p.89).

Para el trabajo con la información elaboramos la Matriz para el análisis general de entrevistas en Excel, la cual nos permitió hacer una codificación abierta y lograr, finalmente, mayor visibilidad de los datos en conjunto, cruce de categorías y filtros de información. En este orden de ideas, después de la consignación de la información en la matriz correspondiente, seleccionamos los párrafos que sirven como unidades de análisis, teniendo en cuenta los cuatro tópicos desde los cuales se estructura la información. Seguidamente, clasificamos los hallazgos en la matriz y mediante el uso de los rótulos o la conceptualización buscamos las denominaciones más comunes correspondientes a las expresiones emitidas por los entrevistados. En este punto debemos destacar que el momento de la rotulación está marcado por un proceso de relectura constante y de revisión de los datos, lo cual provoca cambios permanentes en los rótulos, puesto que en algunas ocasiones éstos se tornan muy generales o relacionados más con aspectos puntuales de la docencia y la didáctica, mientras que la idea es buscar que cada vez los datos nos aporten más información acerca de la conceptualización en torno a nuestro interés: las representaciones de género. Dicho análisis nos permite plantear la siguiente matriz: 


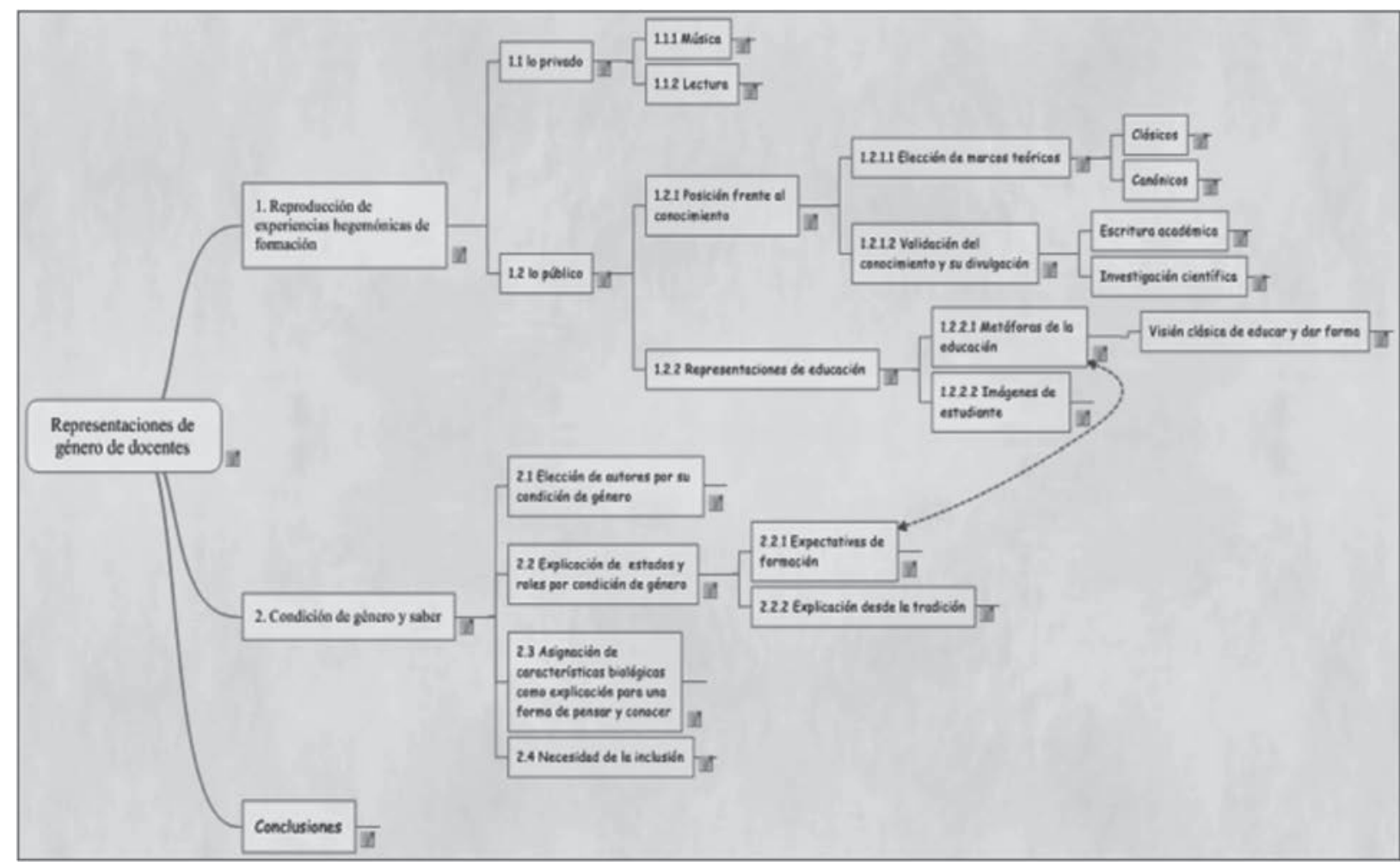

Figura 1: Diagrama de análisis de las representaciones de género, elaboración propia.

El diagrama nos traza rutas posibles para el análisis que planteamos en este trabajo, nos muestra el recorrido posible que emerge de los datos directos de quienes están involucrados en el proceso de formación de maestros de lenguaje. Lo comparamos con esos pisos de las casas viejas, agrietados y corroídos por los años, donde las personas que las habitan han dejado su huella secreta y son los Otros quienes vienen a armar el mapa y a reconstruir los itinerarios desde las ruinas.

En las representaciones, por ende, están involucrados dos aspectos fundamentales: 1) la reproducción de experiencias hegemónicas de formación, desde la posición de los docentes frente al conocimiento y las representaciones de educación que tienden a reproducir; y 2) la condición de género asociada al saber, ya sea desde la explicación generizada de los contenidos, muy anclada en una visión biológica, o desde la necesidad emergente y política de la inclusión. Así las cosas, y dada la abundante in- formación categorizada a partir del análisis de los datos obtenidos para la comprensión frente a las representaciones de género, en este artículo mostraremos algunas de las conclusiones del estudio, que constituyen un abrebocas en tanto invitan a una revisión más profunda de los hallazgos de la tesis en que se inspiran estos caminos. Veamos el desarrollo de los dos elementos que permiten la comprensión del fenómeno, pues en este punto, más que hablar de una teoría estaríamos ubicado en el umbral de las preguntas y las hipótesis.

\section{Experiencias hegemónicas de formación: transeúntes diversos en espacios uniformes}

El currículo está conformado por aquellos saberes hegemónicos que la cultura ha aceptado como válidos, pues “En la escuela, además, tiene lugar el primer encuentro con los conocimientos que conforman el pensamiento lógico-científico [...] como un acercamiento privilegiado a la "verdad" que resulta, por ello, más difícil de cuestionar." (Espigado, 2004, p.114). En 
este sentido, las experiencias de formación de los docentes formadores de formadores hacen parte de ese conjunto de saberes que éstos reproducirán o reconceptualizarán en su ejercicio docente y dentro de estas experiencias, las representaciones de lo masculino y lo femenino, por lo general estereotipadas y uniformes.

En este caso resulta importante que aparezcan,en el ámbito privado, dos elementos vinculados con los gustos personales: la música y las lecturas, que son básicamente gustos que vienen desde lo que se les enseñó en el hogar o desde lo que se vivió en los primeros años de vida. Sin embargo, los datos nos aportan una peculiaridad interesante, pues en las entrevistas estas prácticas también pasan por el tamiz de la racionalidad, en tanto las elecciones de la música y las lecturas personales se relacionan con unos propósitos definidos incluso desde la academia, desde la figura del maestro que "inyecta" o desde "la propuesta" en la que inscribieron los entrevistados sus procesos de formación. Así, entre los docentes entrevistados uno de los argumentos más fuertes para una elección personal es la pertenencia a una generación, evidenciando unos gustos mediados por el componente colectivo fuerte que, al fin de cuentas, valida determinadas elecciones o hace menos adecuadas otras. Veamos:

[...] nos gusta por la edad de uno, por ejemplo, que la famosa música de los 60 y 70, pero igual también a veces, música bailable... que salsa, que... o sea, no hay una preferencia inclusive la misma música clásica; entonces dependiendo como del momento uno escucha música [...] pero que igual manera también hay música que... que ahora uno escucha ¿cierto?... Juanes, me gusta también eh... sobre todo pues por el asunto de... de... su parte mensaje que él nos ha dado, pues como persona (Entrevista Institución Privada 1, 2010).

Como podemos ver en la Entrevista Institución Privada 1, los gustos personales del do- cente están justificados por edad y generación en la que se inscribe, elección que hace a título colectivo y no personal al incluir el pronombre "nos", "nosotros". Así, lo que inicialmente debería ser personal y subjetivo, pasa a ser colectivo y se refuerza mediante la inclusión de un personaje actual y con éxito entre los jóvenes, máxime cuando se hace una contraposición entre lo nuevo y "el tiempo de uno", lo que implícitamente permite entender que éste ya no es el tiempo del entrevistado y por ende, citar personajes de la actualidad es la manera de incluirse en un tiempo que se supone ya no le pertenece.

Asistimos nuevamente a esa escisión entre lo natural y lo culto propio de un contexto de patriarcado de la razón. Esta distinción también se presenta en relación con las prácticas de crianza, pues hay quienes sostienen que sus gustos y elecciones se justifican en tanto esas experiencias son las que se han vivido en el hogar, sin embargo, los argumentos finalmente se alejan de una explicación sencillamente vivencial, la cual se complejiza cuando se alude al criterio de "calidad" tal como lo vemos en la Entrevista Institución Privada 4:

[...] mi hermana tenía un novio que era músico de Antioquia, el tipo vivió unos años en la casa y no escuchaba sino música clásica, entonces en mi casa, por ejemplo, hay una tradición de escuchar música clásica cuando uno va a estudiar, entonces escuchamos Beethoven, Tchaikovsky, Vivaldi, lo que surja para estudiar (Entrevista Institución Privada 4, 2010).

Esta escisión no se da solo en lo que respecta a elecciones personales, pues también es un constante cuando se alude a la formación docente:

A mi encanta siempre leer toda la parte de documentos y textos que tengan que ver con...con...con educación; leo mucho toda la parte de Edgar Morin, de... prácticamente 
la gran mayoría de textos que él ha escrito, artículos, porque considero que uno tiene que estar a la par con la investigación y Edgar Morin lo plantea muy abiertamente ahí en toda esa parte de la formación del individuo, especialmente la formación del docente (Entrevista Institución Privada 4, 2010).

En la entrevista anterior se evidencia una preocupación constante por "la formación del docente" como necesidad de visibilizar el acto educativo mediante este discurso que se ha convertido en demanda de formación para las instituciones de Educación Superior, así pues, podemos ver la ausencia de elementos relacionados con la experiencia subjetiva y del Otro, supeditados a la carga racionalista de nuestro sistema actual de validación del conocimiento.

En este punto, una de nuestras preguntas apunta a develar cuál es la concepción del conocimiento y los saberes que tienen los docentes. En Educación Superior parece adecuado asumir como referentes obligados la lectura de autores y teorías clásicas, centrados fundamentalmente en lo que es considerado canónico en nuestra cultura cada vez más influenciada por lo occidental y eurocentrista, sin que haya un interés real por incluir maneras de acercamiento a otras teorías, aunque desde la verbalidad se desee acceder a ellas. Así pues, en el contexto educativo parece más adecuado citar autores como Piaget, Morin o Foucault sin implicar realmente un cambio en los paradigmas de pensamiento y de la acción docente, ni una apropiación real de su legado. Llama la atención la manera como se invisibiliza otros autores cuyos aportes van en líneas similares, aunque con sus respectivas especificidades, a los cuales se les ha desconocido como portadores de un saber tan válido como los citados arriba.

En este sentido, muchas veces la inclusión de los clásicos no se sustenta exclusivamente en argumentos académicos, pues aparecen elementos como la tradición y la cultura que los valida y los pone por encima de otras maneras de generar y divulgar el conocimiento. En este orden de ideas, uno de los elementos que aparece con más fuerza y que, como hemos visto hasta acá, se vincula con las representaciones de género de los docentes, es el relacionado con las maneras hegemónicas y culturalmente aceptadas de validar el conocimiento que se lleva a las aulas. Así las cosas, la escritura y la investigación, y no la oralidad, sigue siendo un criterio fuerte para otorgarle validez al conocimiento. Desde esta perspectiva, en algunos casos, cuando los entrevistados aluden a la oralidad, lo hacen desde la consideración como complemento de la escritura, pues esta última parece validarse por sí misma, en tanto es altamente valorada en la mayoría de las entrevistas. Sin embargo, en el caso de las mujeres entrevistadas, a la elección de la escritura como elemento definitorio para la validación del conocimiento, aparecen unidas otras formas de comprensión, tales como la imagen o el cuerpo, pero éstas terminan nuevamente por vincularse con otras actividades académicas que las validan.

Por otro lado, cuando los docentes hablan directamente sobre sus concepciones de educación aluden a metáforas en las cuales se superpone la imagen de alguien poseedor de un "don", un "legado" o un conocimiento, frente a la de otro que desconoce $y$, por ende, necesita ser "moldeado" en un ejercicio que supone un ejercicio de poder del saber con el fin de dar una forma preestablecida desde el "debe ser".

[...] para mí la educación...es un trabajo de...diríamos...moldeadores (silencio) con arcillas muy frescas, me refiero a que cuando un profesor recibe un curso, la institución estatal, la comunidad, los padres de familia, le dicen a ese profesor: ahí le entregamos esa arcilla esos niños, esos jóvenes...profesor moldéelos (Entrevista Institución Pública 1, 2010).

En este orden de ideas, las imágenes que producen los maestros de sus estudiantes re- 
presentan la idea que tienen de éstos en virtud de sus cualidades similares a las realidades que conocen y valoran. Así pues, ante la petición explícita de que representen en un dibujo su idea de estudiante, las imágenes se inscriben en unas dinámicas muy similares que nos permiten reconocer dos enunciaciones: una que se enmarca en las lógicas de la objetivación mediante la representación del estudiante como cosa u objeto, y otra que se instala en la descripción literal de lo que hay y en la cual se inscriben las representaciones antropomórficas planas y unidimensionales. Ambas representaciones gráficas de carácter social, incluyen tanto la dimensión histórica como la cultural de los docentes y constituyen su manera de percibir la categoría de género, la imagen del Otro.

Siguiendo a Rosa Vásquez (2004), podemos asegurar que estamos ante unas experiencias que se legitiman en formas de pensamiento supuestamente correspondientes a hombres y mujeres, pero que terminan siendo maneras de actuación o de lectura de la realidad desde "[...] claves y referentes masculinos en la explicación, comprensión y representación de la realidad social y cultural" (p. 147). Lo más significativo en estos referentes es que, como lo muestran las entrevistas, se activan sin tomar consciencia de ello y actúan así en nuestro imaginario, como cuando decimos ingeniero y nos imaginamos a un hombre y decimos maestro y nos imaginamos a una mujer, ¿dónde está, entonces, la alteridad, el Otro a quien no tenemos el derecho de encasillar y negarle su porción de impredecible?

\section{Condición de género y saber: despertando paredes con los dedos en las llagas}

Durante nuestro trabajo de análisis de las entrevistas realizadas a los docentes formadores de formadores, nos encontramos con que, además de esa asociación constante entre género y la reproducción de experiencias hegemónicas de formación, hay un vínculo entre el saber y la condición de género. Dentro del protocolo de entrevistas las preguntas referidas tanto a las experiencias y actitudes docentes como al quehacer en la profesión, dan cuenta de la idea general que tienen los maestros sobre el lugar del otro en los procesos que orientan. Así pues, las representaciones de género de los docentes están asociadas, también, de manera directa, con unas estrategias particulares de acercarse a los conocimientos y saberes.

Intentar ser incluyente, simular reconocer al Otro, es una tarea conveniente y bien vista cuando se trata de formadores de formadores, quienes al situarse en el plano de la perspectiva de género, le responden a la sociedad el encargo político y a la academia su necesaria ubicación en los marcos teóricos contemporáneos; sin embargo, miramos con sospecha tal inclinación, en tanto sabemos que el hecho de nombrar de manera consciente y racional algunas referencias femeninas no garantiza su reconocimiento real, compartido y experiencial.

Así las cosas, cuando los maestros citan mujeres escritoras en el panorama de sus lecturas personales o marcos teóricos, no necesariamente están reconociéndolas como parte del esquema conceptual y cognoscitivo humano. Llama la atención que dichos nombres no se reconozcan por sus potencialidades en la escritura o por lo que éstas significan para la historia común, pues se justifica su aparición desde su condición de género femenino, contrario a lo que sucede con autores masculinos quienes no requieren este tipo de salvedades. Veamos:

[...] entonces, por ejemplo, uno lee a Freud y los textos de Freud son de una calidad impresionante y al mismo tiempo hacen parte de la formación en un saber específico; ahorita últimamente está en boga esta filosofa Martha Nussbaum, igual... una literatura muy agradable y también con un contenido y así muchos autores, muchísimos que podríamos mencionar (Entrevista Institución Privada 2, 2010). 
En este caso se menciona a un autor cuyos textos son considerados de "calidad impresionante"; este apelativo claramente contrasta con la referencia a la autora de quien se dice posee una "literatura muy agradable". Nos interesa aquí la carga semántica de uno u otro término, pues el primero sin lugar a dudas marca una escisión frente al segundo entre lo que se considera académico y aquello que puede divertir, amenizar. Este segundo término, entonces, parece ser más superfluo, impreciso, menos pesado que el primero que hace parte de una formación específica. A partir de lo que evidenciamos aquí, en estos casos, lo importante no es compartir realmente el gusto por autores de ambos géneros, sino más bien, dar la sensación de que se incluyen ambos, pese a lo cual las valoraciones frente a sus características científicas o técnicas continúan marcando una diferencia entre aquello que es validable desde la objetividad y lo que se considera asociado al sentimiento y a la subjetivad.

Es claro, pues, que mencionar la necesidad de "recuperar" la mujer escritora mediante la mención de unos pocos nombres canónicos no es ni siquiera un paso hacia la construcción de una representación vital del Otro, sino más bien una manera de ahondar aún más en la exclusión, asunto bastante distante de una propuesta de género planteada desde la base o desde aquellos elementos que, como hemos visto hasta aquí, consideramos irrelevantes o naturales, pero que dan cuenta de la vigencia de dicho desconocimiento frente al Otro.

En esta línea, también aparecen palabras desde las cuales se intenta reconocer una nueva condición para la mujer en la sociedad, aunque no podemos pasar por alto que nuevamente dichas apreciaciones se inscriben en la supuesta necesidad de aceptación y reconocimiento que ella requiere desde lo masculino, veamos:

[...] en una experiencia que nosotros tenemos de la Licenciatura en Etnoeducación con indígenas, nos ha llamado la aten-

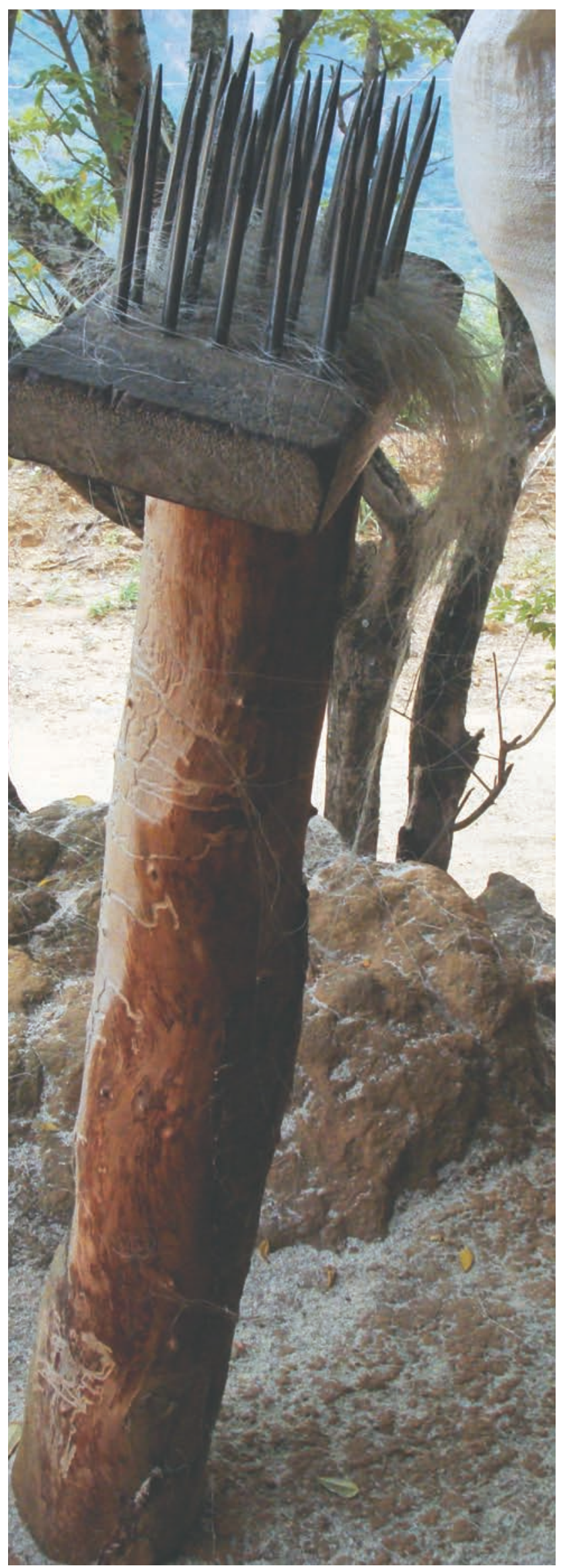


ción..., incluso yo animo mucho a las indígenas y aplaudo cómo muchas ya han llegado a la universidad, se han comprometido a estudiar a pesar de que todavía dentro de los grupos étnicos indígenas, es tan... todavía el machismo es tan fuerte y que... que la mujer en muchas comunidades prácticamente a los 13 o 14 años ya disque tiene que estar casada y... y dedicarse a las labores domésticas; hoy ya muchas niñas es... ya... ya están pensando distinto y están terminado su bachillerato y están buscando llegar también a la universidad. (Entrevista Institución Privada 1, 2010)

En las palabras anteriores aparece la expresión "niña" para referirse a la mujer indígena, con lo cual se le infantiliza, no solo desde su condición aborigen sino también desde el hecho de ser mujer y joven; así mismo, concepciones que aparentemente reivindican el papel activo de la mujer en la sociedad actual, no son otra cosa más que la muestra de un interés político por seguir las directrices de instituciones tanto o más poderosas que la misma escuela; así pues, consideramos que gran parte de estas palabras y acciones buscan inscribir a la mujer en un sistema ya fundamentado desde lógicas externas a ella misma, creadas por otros, desde los mismos sistemas de valores patriarcales estructurales. Así las cosas, nuestra sociedad, "[...] en lugar de traspasar con su crítica esa estructura simbólica, la asume y le otorga validez universal" (Moreno, 2006, p. 123). De esta manera, la mujer está en desventaja, se le disminuye a la impotencia de su espera constante por el reconocimiento que siempre viene de otros, supuestamente capacitados para hacerlo.

Otra condición asociada al saber en relación con la profesión docente y que determinan la representación del Otro, de la mujer, en este caso, es el vínculo entre mujer y maestra. Desde esta perspectiva, como lo señala Rodríguez:

El discurso sobre las características femeninas de la profesión docente se intenta im- poner para salvaguardar la feminidad de las maestras [...] las consecuencias de la construcción de perfiles diferentes para maestros y maestras es el deterioro profesional del modelo que se construye para las maestras (2004, p. 177).

Hemos visto cómo las representaciones de mujeres y hombres relacionadas con el vínculo entre género y saber aparecen mediadas por unas características y roles naturalizados y hegemónicos que hacen parte de los sistemas de formación en los cuales nos hemos inscrito unas y otros, con o sin intención de validarlos.Así, la exclusión de las mujeres en el plano académico y científico ha estado determinada por elementos de la tradición, la fuerza de la costumbre que nos lleva a la comodidad de los espacios conocidos y al temor de construir los propios y cuestionarnos sobre aquello que hemos aceptado de antemano como única verdad posible. De esta manera, nos encontramos ante maneras poco cuestionadas de asumir la imagen de unas mujeres disminuidas con respecto a unos hombres que culturalmente han podido nombrarse y elegir maneras de accionar libres.

\section{Conclusiones}

En este trabajo hemos esbozado algunos elementos de análisis alrededor del tema de las representaciones de género que abren la puerta para una discusión profunda en torno a las representaciones de lo Otro (el otro, la otra, lo diferente), propuestas como alternativa para pensar el papel de la alteridad en la formación de maestros en un mundo contemporáneo saturado de discursos reivindicativos de la diferencia que no terminan de parecernos sospechosos, en tanto como lo anunciamos aquí, pese a que la presencia femenina cada vez es mayor en diferentes ámbitos de la vida pública, no podemos desligarnos de los problemas que siguen existiendo en cuanto a los estereotipos, la apropiación de la ciencia y de los discursos. 
En este mismo sentido, Susi (1994) reclama la "[...] necesidad de una autoridad femenina para que la autoridad que viene dada por la comunidad científica sea plena y, por tanto, comprenda y haga significativa nuestra experiencia femenina en el mundo" (p.203).

Así pues, según los resultados de nuestra investigación no es muy claro aún, ni en la ley ni en la práctica, la manera como asumen los docentes involucrados en los procesos educativos de la formación de formadores las mencionadas disposiciones de inclusión de la diferencia que, al convertirse en demandas, sitúan a los maestros en el ámbito de lo público y de una realidad que se supone ya está determinada por los sistemas dominantes. Parece claro, pues, que demandas como la presencia de autores canónicos, las teorías de la educación aceptadas por la porción de la población que se considera la voz válida, la investigación y la escritura como únicas posibilidades de divulgación del conocimiento.Es decir, la cultura de lo escrito en contraposición con formas subjetivas mediatizadas por lo oral, que continúa siendo el único indicador de la dignidad de un saber que pretende ser enseñado, hacen parte de un sistema de valores establecidos por una hegemonía, la cual, pese a no ser un secreto para nadie, continúa enmascarando su accionar en la idea de un deber ser que no admite la inclusión de otras maneras de conocer.

Por ende, nuestra apuesta es por la categoría de género como una posibilidad estética para los maestros.En ese sentido es necesario señalar que la palabra estética alude a lo que se percibe por los sentidos, lo que permite el acceso a lo sensible. Los seres humanos somos seres sensibles por definición y por naturaleza, y es precisamente esa percepción sensible lo que nos permite llevar a cabo la experiencia de formación de llegar a ser lo que somos. Así pues, ser parte de la naturaleza y a la vez tener que apartarnos de ella para transformarla en acontecimiento estético, creativo, hace parte de una contradicción vital que nos obliga al reconoci- miento de lo diferente y a la posibilidad de ser cuando somos Otro, convirtiendo la vivencia con el Otro en una experiencia estética.

Para nosotros es claro que abordar el tema de género y educación, en la manera como lo presentamos aquí, deberá permitir establecer una relación entre las potencialidades del quehacer docente y el reconocimiento del Otro, más allá de lo que se supone establece la ley como política de un Estado liberal. Así las cosas, teniendo en cuenta que el maestro formador de formadores construye una visión de mundo, pues en esto consiste su oficio, es necesario preguntarnos si en los maestros existen representaciones de género propias, pensadas e interiorizadas desde las prácticas, si éstas realmente sitúan al Otro en el punto intermedio del afuera y la propia subjetividad y, por tanto, se convierten en experiencia estética, permean realmente sus quehaceres desde el adentro que tantas veces se la ha usurpado al maestro. Como se puede ver, la pregunta ya no sólo es por la condición del profesional en el ámbito del poder, sino la manera como repercuten en la sociedad sus prácticas como una evidencia de ese poder creativo que, aunque limitado al escenario de la institución, incluye un componente estético que se refleja, entre otras acciones, en las creaciones metodológicas, didácticas y en la modificación cognoscitiva que conlleva consecuencias futuras para la formación de sus estudiantes. En este marco, la tarea para los maestros es doble: "[...] la de educar como un acto de conducir a los sujetos a su propio marco de sujeción y la de convocar al mismo sujeto a su afirmación como ser libre y emancipado, esta última convocatoria es pedagógica, trasciende la naturaleza empírica de las conductas y reclama la posición de los espíritus" (Ibarra, s.f. p. 28).

Dentro de las dimensiones de la educación el reconocimiento del Otro como posibilidad de conocimiento, moral y estética, tiene validez en el concepto de representaciones de género más amplio, alejado de hegemonías justificadas solo desde historias reduccionistas, 
en tanto abarca todas las dimensiones de la formación, incluidas las formas del trato entre los seres humanos y los estilos de la sociabilidad, entendida como padecer con o sentir con. En esta relación la educación se vincula con el conocimiento de valores sociales como el de la libertad, posible entre los maestros que son sometidos a ésta y que, por tanto, luego habrán de imponerla incluso a costa de su naturaleza. En este sentido, la educación ha de entenderse como una educación política encaminada a la democratización y los actuales formadores de formadores como los posibles actores de esta nueva manera de educar en la diversidad.

Ese ser más humano que puede ser el educador, ha creado metáforas que le han posibilitado comprender el mundo, dirigirse al entorno y acomodarse a las circunstancias, solo que por momentos ha olvidado que en su tarea de formar a otros seres humanos, es en el Otro donde se fundamenta su experiencia, pues somos huellas del Otro que a su vez dejará las marcas que unos más reconocerán y recorrerán en busca de sí mismos. Entonces, en educación solo nos queda preguntar ¿qué es lo que el Otro no puede hacer?

\section{Referencias}

Bachelard, G (1993) La poética de la ensoñación. México Fondo de Cultura Económica

Butler, J. (1990). Actos performativos y constitución del género: un ensayo sobre fenomenología y teoría feminista. Johns Hopkins University Press, 270 - 282.

Butler, J. (2001). Mecanismos psíquicos del poder. Teorías sobre la sujeción. Madrid: Ediciones Cátedra. Instituto de la mujer. Traducción: Jacqueline Cruz.

Butler, J. (2007). El género en disputa. El feminismo y la subversión de la identidad. Barcelona: Paidós.

Canavessi, J.J. (1998). Historia de las mentalidades: marco teórico y estado de la cuestión. Recuperado de http:// www.sagrado.edu.ar/boletin/bole32/mentalidades. pdf.

Espigado, G. (2004). Historia y genealogía femenina a través de los libros de texto. En: Rodríguez, C. (Comp). La ausencia de las mujeres en los contenidos escolares (113- 144). Buenos Aires: Miño y Dávila.

Flick, U. (2007). Introducción a la investigación cualitativa. (Segunda edición). Madrid: Morata, Paideia.

Ibarra, Ó.A. (s.f). La función del docente: entre los compromisos éticos y la valoración social. Recuperado de http://www.oei.es/docentes/articulos/funcion_docente_compromisos_eticos_ibarra.pdf

Moreno, A. (2006). Más allá del género: aportaciones noandrocéntricas a la construcción de un humanismo plural. En: Rodríguez Martínez, C. (Comp). Género y currículo. Aportaciones del género al estudio y práctica del currículo. (103-130). Madrid: Ediciones Akal.

Navarro, M. y Stimpson, K. (1999). Sexualidad, género y roles sexuales. Argentina: Fondo de Cultura Económica.

Pérez Alonso- Geta, P. (noviembre de 2007). Lectura y género: leyendo la invisibilidad. Universidad Autónoma de Barcelona,. 1- 54.

Silva, R. (2007). A la sombra de Clío. Diez ensayos sobre historia e historiografía. Medellín: La carreta histórica.

Susi, E. (1994). Ciencia y género: Autoridad y medida en la enseñanza. Enseñanza de las Ciencias 12 (2), 200-205.

Vásquez, R. (2004). La negación de lo femenino en las instituciones educativas. En: Rodríguez Martínez, C.(Comp). La ausencia de las mujeres en los contenidos escolares. (145- 168). Buenos Aires: Miño y Dávila.

Strauss, A. y Corbin, J. (2002). Bases de la investigación cualitativa. Técnicas y procedimientos para desarrollar la teoría fundamentada. Medellín: Editorial Universidad de Antioquia. 